\title{
A Study of Effectiveness of Custom Skill Program (CSP) - A form of e-learning in D's Entertainment Pvt. Ltd. Bhilwara, Rajasthan
}

Dr. Pratima Sanadhya, Assistant professor, International School of Management \& Research, Pune Email: sanadhyapratima@gmail.com

\section{ABSTRACT}

Key Words:

Customer Skill Pro, eLearning, online learning
This paper aims towards the study of Custom Skill Program (CSP) or what it is commonly called as Custom Skill Pro which is an online portal where we can access eLearning courses anytime. The Digital media companies now a days are becoming employee oriented, they focus on employee skill enhancement which is beneficial for both the employer and for the employee. The CSP has limitless possibilities of learning so we can take course \& assessment anytime to test \& enhance skill set. It is a simple \& easy way to learn using interactive audio \& video courses also. Since the employees are newly introduced into the organization, it is the time when they have to focus on their development \& productivity. This study will help us in understanding how effective is the CSP in today's scenario.

\section{Introduction:-}

\section{CSP (Custom Skill Pro):-}

To enable and empower to stay ahead on the learning curve and spearhead the capability building agenda for career growth and development in IT sector, the HR team of various organizations generates a specific and précised interface Custom Skill Program (CSP). The CSP aims to focus on online learning delivery, manage instructional content, administer test, assignments \& track an employee's learning progress. Custom Skill Program (CSP) is an online portal where we can access eLearning courses anytime in the organization. It has limitless possibilities of learning so we can take course \& assessment anytime to test \& enhance skill set. It is a simple $\&$ easy way to learn using interactive audio $\&$ video courses also. The present study will help the companies as the employees will be able to learn and access wide range of training and courses, making them more knowledgeable and effective. It will also reduce the off-line training time of the employees.

Custom Skill Program contains seven different sections of courses \& these sections have number of modules categorized according to sections.

Seven different sections are:-

1) Compliance Training

2) Creative Design

3) Management

4) Product Training

5) Quality

6) Soft Skill Training

7) Software Training

Key Highlights of Custom Skill Program (CSP):-

1) Build practical competencies: -

Competence is the ability of an individual to do 
a job properly. A competency is a set of defined behaviors that provide a structured guide enabling the identification, evaluation and development of the behaviors in individual employees.

\section{Benefits of building practical competencies: -}

1) Training \& Development

2) Performance Management

3) Career Paths

4) Succession Planning

\section{2) Self-explanatory \& Self-paced: -}

It is clear and easy to understand without needing any extra information or explanation. Self-paced courses do not follow a set schedule. Course materials are completely available as soon as the course begins.

Assignments and quizzes do not have start or due dates. The course shows indicators for graded assignments, but not due dates. You can complete assignments and exams at your own pace, as long as you complete all course work before the course ends.

\section{3) Certification post each course completion:}

After completion of each course on CSP the employees get the Certificate of completion of the course which is generating immediately after employee submits the quiz. Employee can reach to certificate by visiting own profile on CSP. The certificates are saved on each employee's profile.

\section{Statement of the problem-}

Custom Skill Program is an online portal where one can access eLearning courses anytime in the organization. It has limitless possibilities of learning so we can take course \& assessment anytime to test \& enhance skill set. It is a simple $\&$ easy way to learn using interactive audio $\&$ video courses also. It has been analyzed by various studies that even in today's scenario many of the employees are still not aware of the courses and how they can get benefited from these courses and training modules. Thus, it is necessary to make them aware of this program. Also, it is important to understand how much it is effective and to what level it is beneficial from the employees. Thus, the present study aims to identify the effectiveness of the program and to analyze the satisfaction level of the employees in the organization.

For the study, a sample of 40 respondents of D's Entertainment Pvt. Ltd of wing "A" \& wing "B" of Bhilwara has been selected under study to analyze the results.

\section{Literature Review}

According to Tagreed Katonah, Prof. Musa AlLozi. (2016) there is a need to study the current e- learning environment with special reference to CSP including the characteristics, limitations, advantages and the major factors that affect the acceptance of such technologies. It is concluded that a successful e-learning system should consider the personal, social, cultural, technological, organizational and environmental factors.

B. A. Buhari (2017) aimed at the study of CSP as an improved E-Learning System. He explained that the system is aimed at being user-friendly, reliable and improved with better specifications. To ensure proper interaction between students and lecturers, this proposed system incorporate audio calls to lecturers through Skype and also video conferencing through webinar (Web Based Seminar); a software that enables lecturers deliver lecture live. It gives the system the ability to give, receive, and discuss information in real time.

CSP is one of the most used technologies in the IT industry this modern time. CSP is basically a 
learning platform that applies the utilization of electronic media and information and communication technologies (ICT). E-learning can be implied as other alternative terms such as online education, computer-based training, technology-enhanced learning and others. The implementation of e-learning has been carried out in multiple education departments and learning institutional levels. The usage has also broadened within some corporate and professional companies, in informing their staffs and customers on any related development occurs within their business world (Hisyamuddin Hashmi, Zaiden Tasir 2014).

The background of e learning was studied history and in the next section its effectiveness in learning was briefly examined. The overall benefits of CSP in e-learning include the promotion of learning, independence and individual satisfaction, learning at anytime, anywhere and with any background, learning without the same prerequisites, speed and process of learning due to individual needs, individual learning along with cooperative learning, saving time and costs significantly, the possibility of teaching and learning for all people, mutual teaching and learning, getting quick results in learning, learning more by using multimedia and maintaining resources and reducing environmental and audio pollution (Mousazadeh Somayeh, Maryam Dehghani, Forzani Mozaffari- "The effectiveness of CSP in E- learning."(2016).

\section{Objectives}

- To identify the effectiveness of CSP in D's Entertainment Pvt. Ltd.

- To analyze the satisfaction level of employees.

- To understand the expectations of employees of D's Entertainment Pvt. Ltd from CSP.

\section{Research Methodology}

The present study is confined to the study of effectiveness of Custom Skill Program (CSP) among the employees in D's Entertainment Pvt. Ltd. Bhilwara, Rajasthan.

\section{Population:}

The employees of D's Entertainment Pvt. Ltd.

\section{Sample Frame:}

The employee with less than one year experience working with D's Entertainment Pvt. Ltd as well as the new joiners signifies the sample frame of the research.

\section{Sample Size:}

A sample of 40 employees from a total of 150 employees having less than 1 year experience as well as the new joiners have been selected.

\section{Sample Type:}

Since the new joiners and those who have not yet completed one year in the organization are bound to experience stress because of new work environment, policies \& practices the sample has to include employees with less than one year experience in the organization as well as those who have recently joined the organization. Therefore, stratified random sampling and convenience sampling technique was selected while preparing and analyzing the questionnaire as this was the only technique that helped to draw conclusions accurately. Thus, the sample of 40 respondents is a mix of the new joiners as well as employees with less than one year working experience with the organization plus whose education qualification is graduate with income ranges from 2 to 5 lakhs.

- Descriptive research design which includes surveys, facts and findings was used in this study.

\section{Methods of Data Collection.}

The questionnaire was distributed among the eligible participant and were to be filled by them. The researcher explained the questions to the participant who were unable to the implications of the given questions and helped 
in filling up the questionnaire.

\section{Tools for Data Collection}

Primary and Secondary sources of data have been used for the research wherein for primary data collection questionnaire technique has been used. The questionnaire utilized for the purpose of research was a semi-qualitative one. The questionnaire dealt with different aspect of the CSP like, "does your company provide you an opportunity of e-learning", "The floor sessions for awareness of CSP are useful", "is CSP user friendly", etc.

\section{DATA ANALYSIS}

1) Does your organization provide an opportunity of eLearning courses?

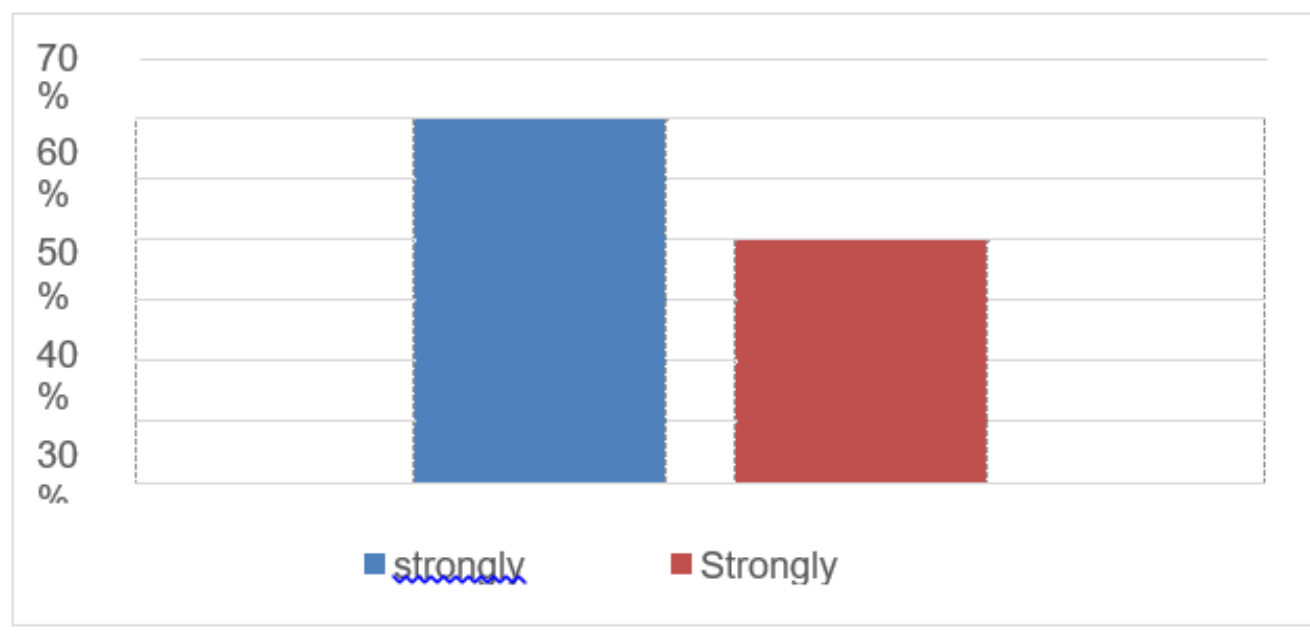

\section{Interpretation: -}

According to the above chart gives a clear view that $60 \%$ of our employees strongly agree that our organization provides an opportunity of eLearning courses. $40 \%$ of our employees agree that our organization provides an opportunity of eLearning courses.

2) The floor sessions for awareness of Custom Skill Program are useful.

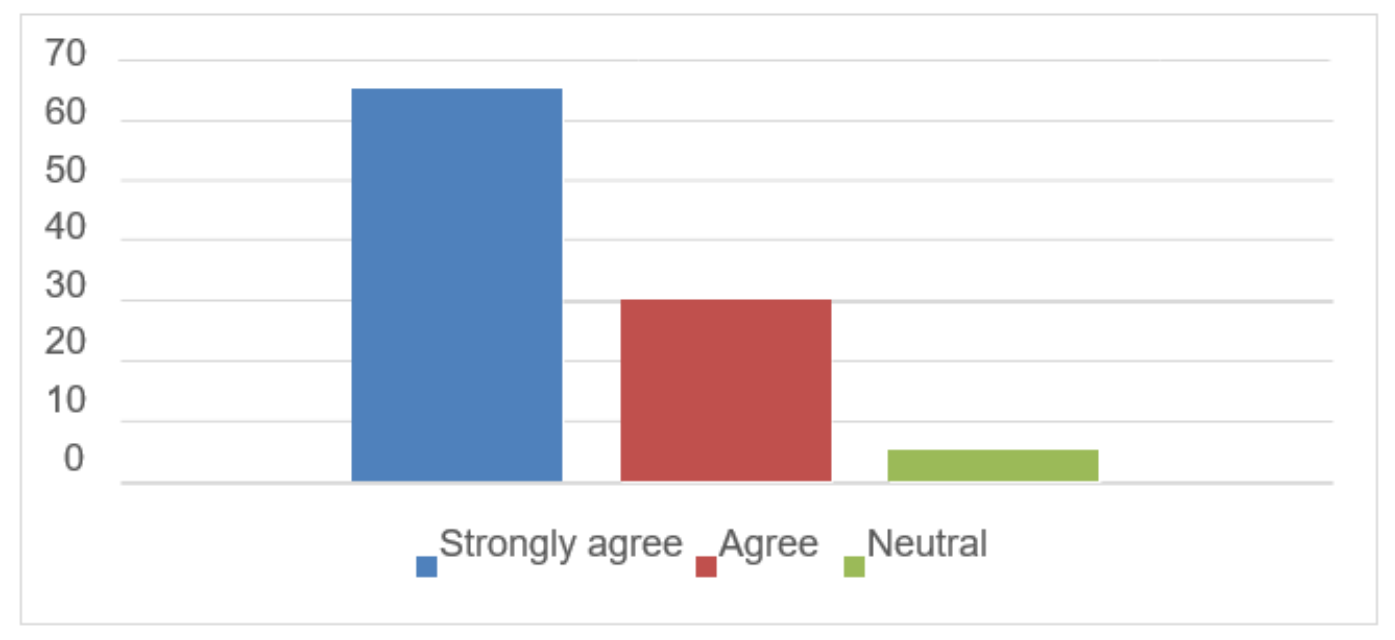

\section{Interpretation: -}

According to the above chart, about $65 \%$ of the employees strongly agree that floor sessions for awareness of CSP are useful. 30\% of employees agreed that floor sessions for awareness of CSP is useful. $5 \%$ of the employees were responded neutral that floor sessions of CSP are useful. 
3) Are you satisfied with the CSP program

provided in your organization?

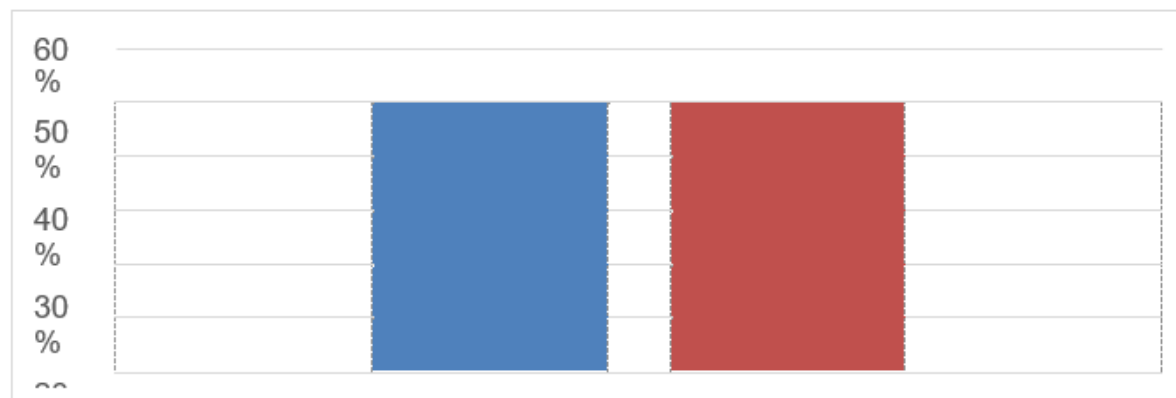

- Strongly agree

\section{Interpretation: -}

According to the above chart, about $50 \%$ of the employees strongly agree that CSP is user friendly. $50 \%$ of the employees agree that CSP that they are not satisfied.

4) Time duration for each course in Custom Skill Program is sufficient.

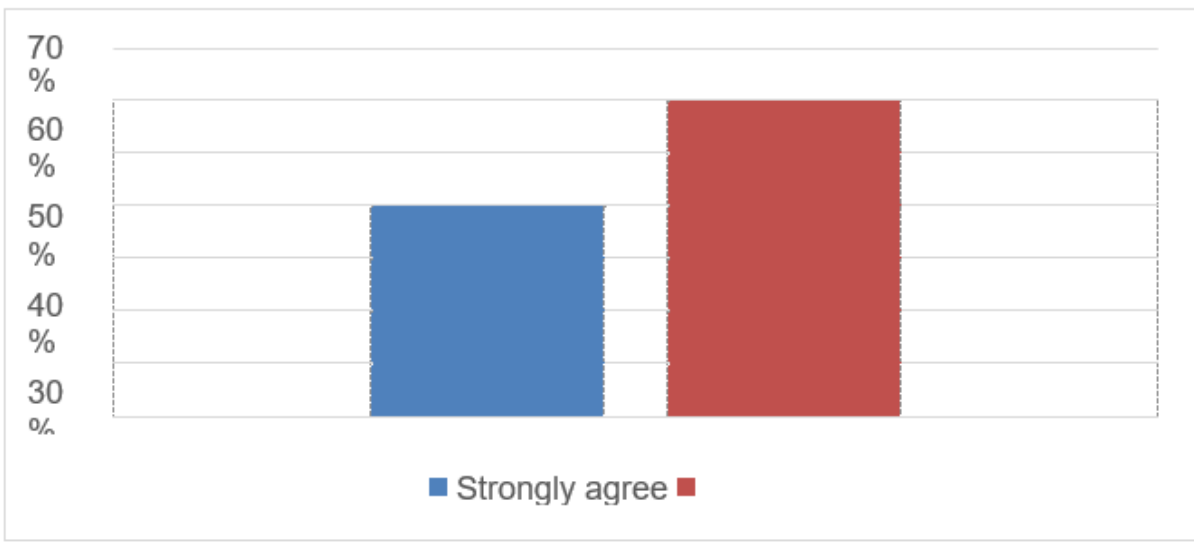

According to the above chart, about $60 \%$ of the employees strongly agree that the time duration for each course in CSP is sufficient. $40 \%$ of the employees agree that the time duration for each course in CSP is sufficient.

\section{5) Course description in Custom Skill Program is sufficient}

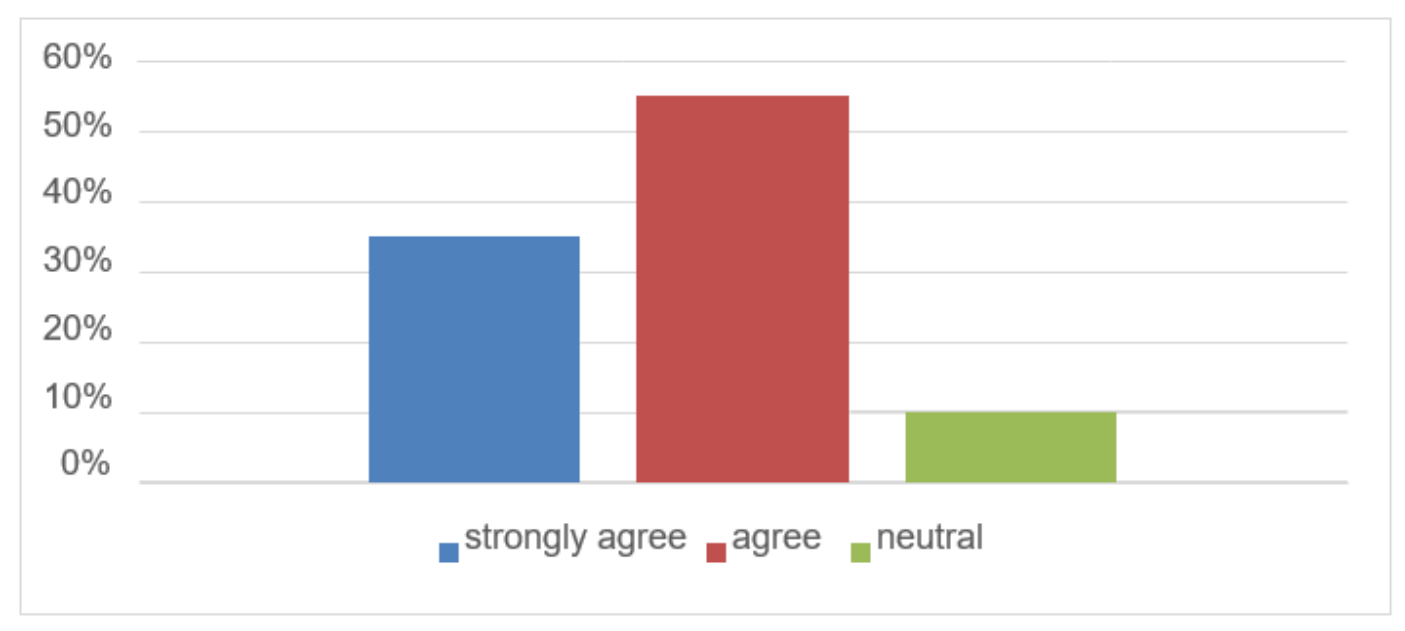




\section{Interpretation: -}

According to the above chart, about $35 \%$ of the employees strongly agree that the course duration in CSP is sufficient. $55 \%$ of the employees agree that the course duration in CSP is sufficient. $10 \%$ of the employees responded neutral that the course duration in CSP is sufficient.

6) Is the process of attending course in Custom Skill Program is self-explanatory?

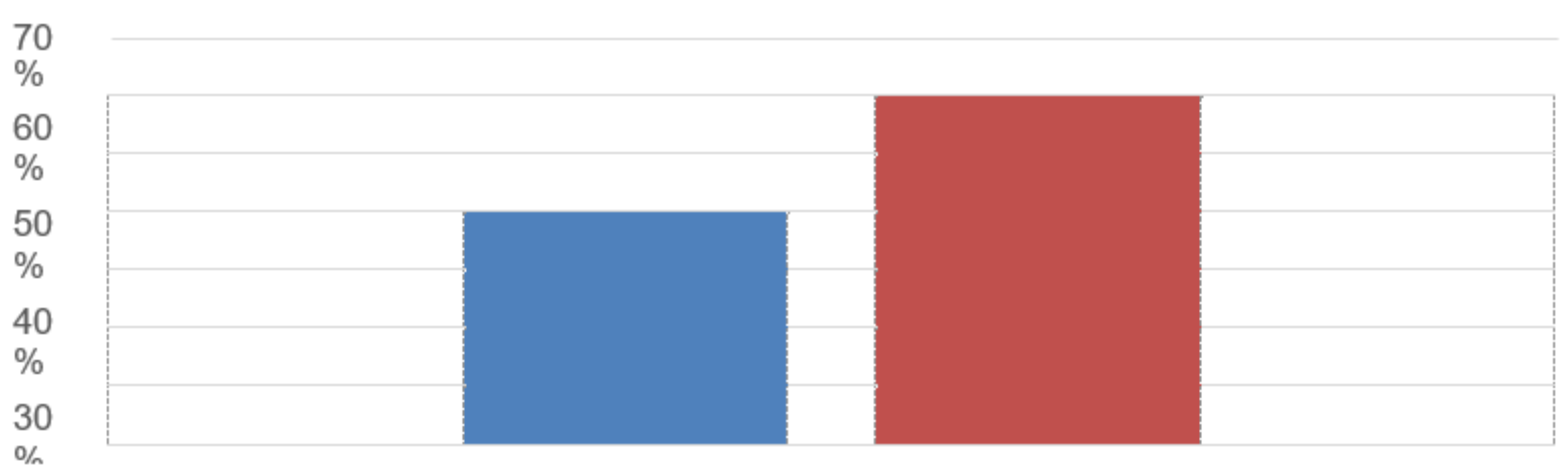

mstrongly agree

\section{Interpretation: -}

According to the above chart, about $40 \%$ of the employees strongly agree that the process of attending course in CSP is self-explanatory. $60 \%$ of the employees agree that the process of attending course in CSP is self-explanatory.

7) Is Course content is helping you in your job and its application?

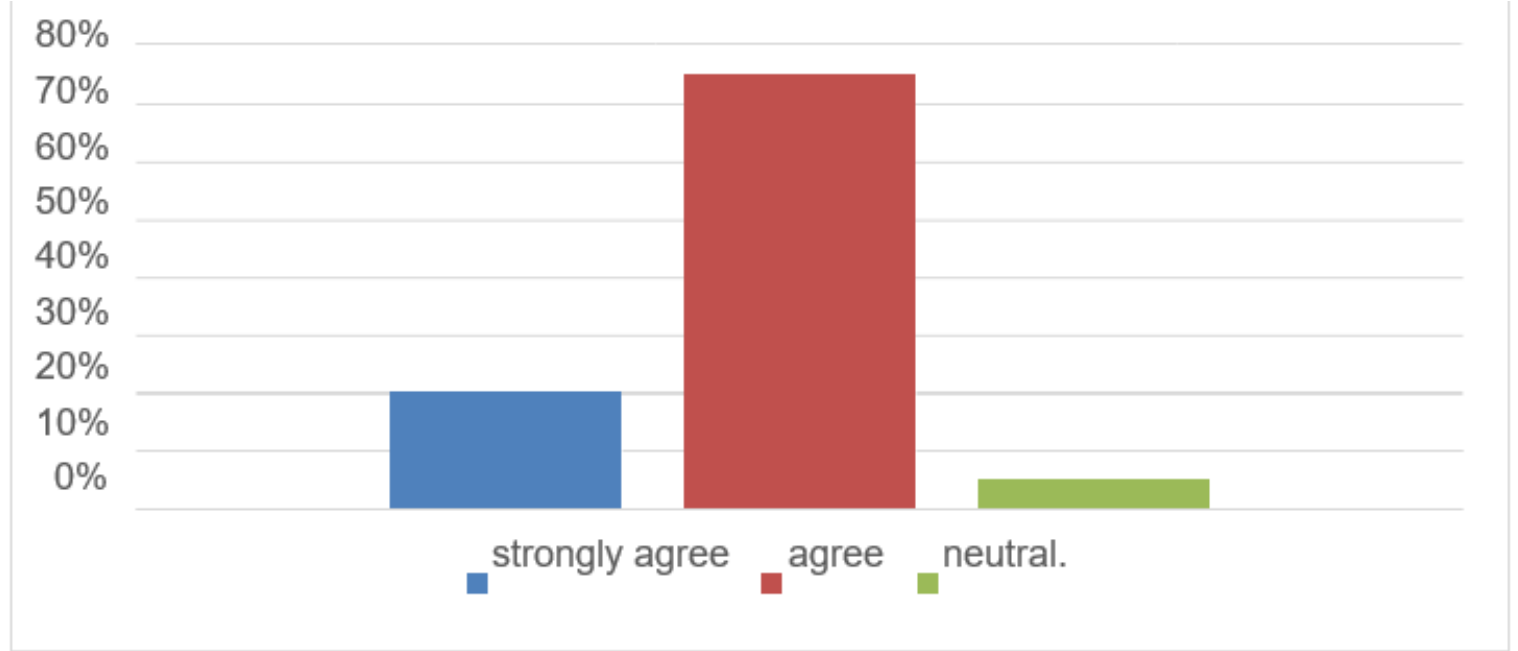

\section{Interpretation: -}

According to the above chart, about $20 \%$ of the employees strongly agree that Course content is perfect and helping them in their job. $75 \%$ of the employees agree that course content is perfect. $5 \%$ of the employees responded as neutral.

8) The courses in Custom Skill Program are having too much pictures/ flashy data/exposed material. 


\section{Available at: $\underline{w w w . i m p e r i a l p u b l i c a t i o n s . c o m}$}

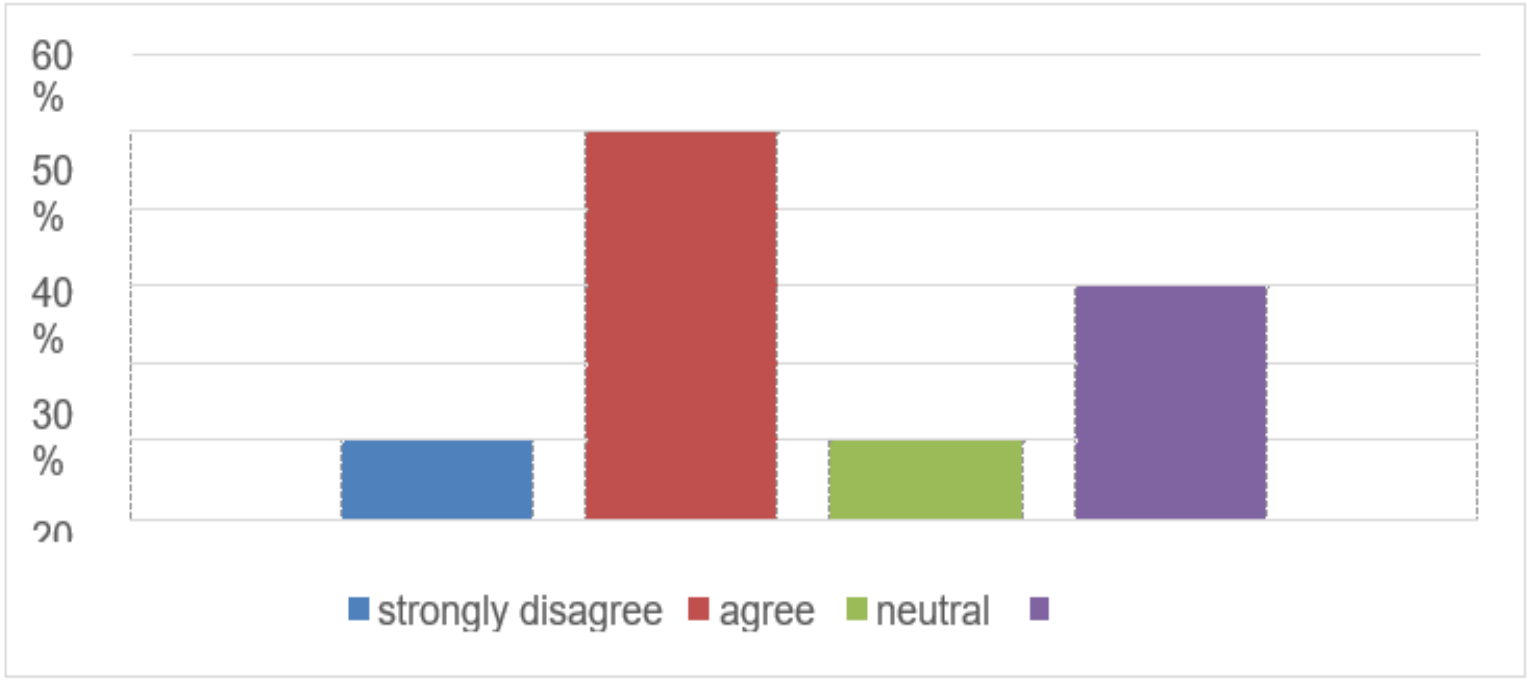

\section{Interpretation: -}

According to the above chart, about $50 \%$ of the employees agree that the courses in CSP are having too much pictures/ flashy data/exposed material where $30 \%$ disagree. $10 \%$ of the employees responded the courses in CSP are having too much pictures/ flashy data/exposed material is neutral. $10 \%$ of the employees strongly disagree that the courses in CSP are having too much pictures/ flashy data/exposed material.

9) Course material needs to be more descriptive

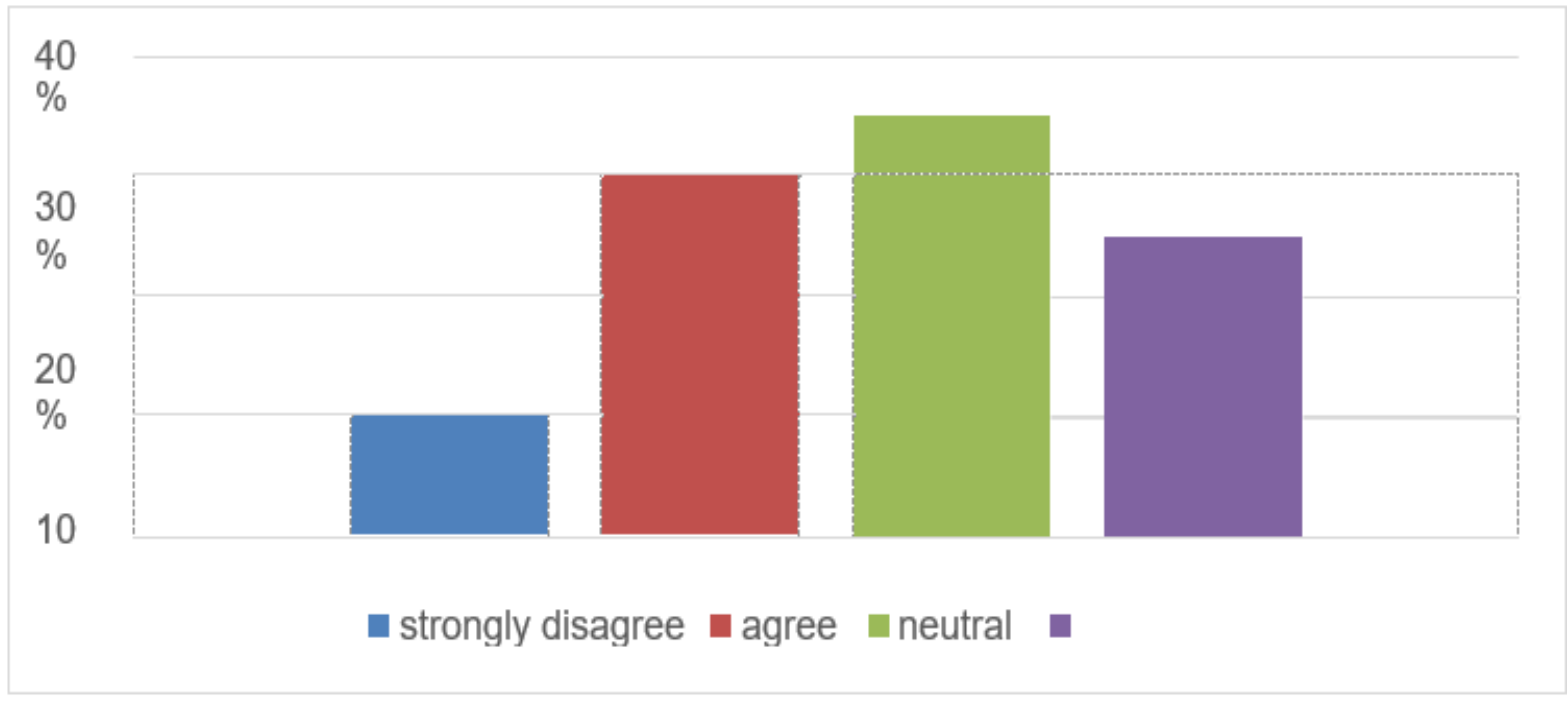

\section{Interpretation: -}

According to the above chart, about $10 \%$ of the employees strongly agree that course material needs to be much descriptive. $30 \%$ of the employees agree that course material needs to be more descriptive where $25 \%$ disagree. $35 \%$ of the employees responded course material needs to be more descriptive is neutral.

10) The course material is useful for understanding of the respective subject 
Available at: www.imperialpublications.com

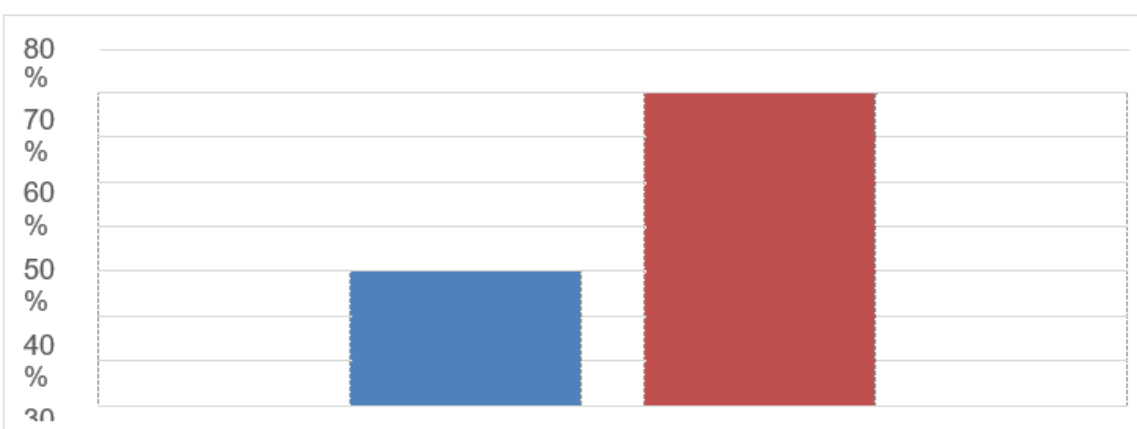

- Strongly agree

\section{Interpretation: -}

According to the above chart, about $30 \%$ of the employees strongly agree that the course material is useful for understanding of the respective subject. $70 \%$ of the employees agree that the course material is useful for understanding of the respective subject.

11) While solving the quiz the time limit is sufficient

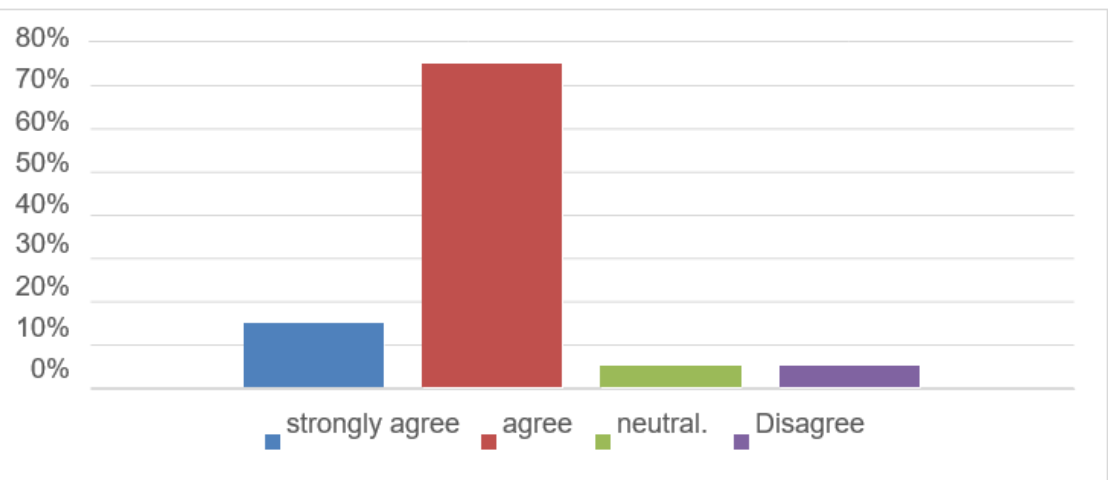

\section{Interpretation: -}

According to the above chart, about $15 \%$ of the employees strongly agree that while solving the quiz the time limit is sufficient. $75 \%$ of the employees agree that while solving the quiz the time limit is sufficient where $5 \%$ of the employees are disagree. $5 \%$ of the employees saying while solving the quiz the time limit is sufficient is neutral.

12) The module has helped me to develop my own technical \& soft skills.

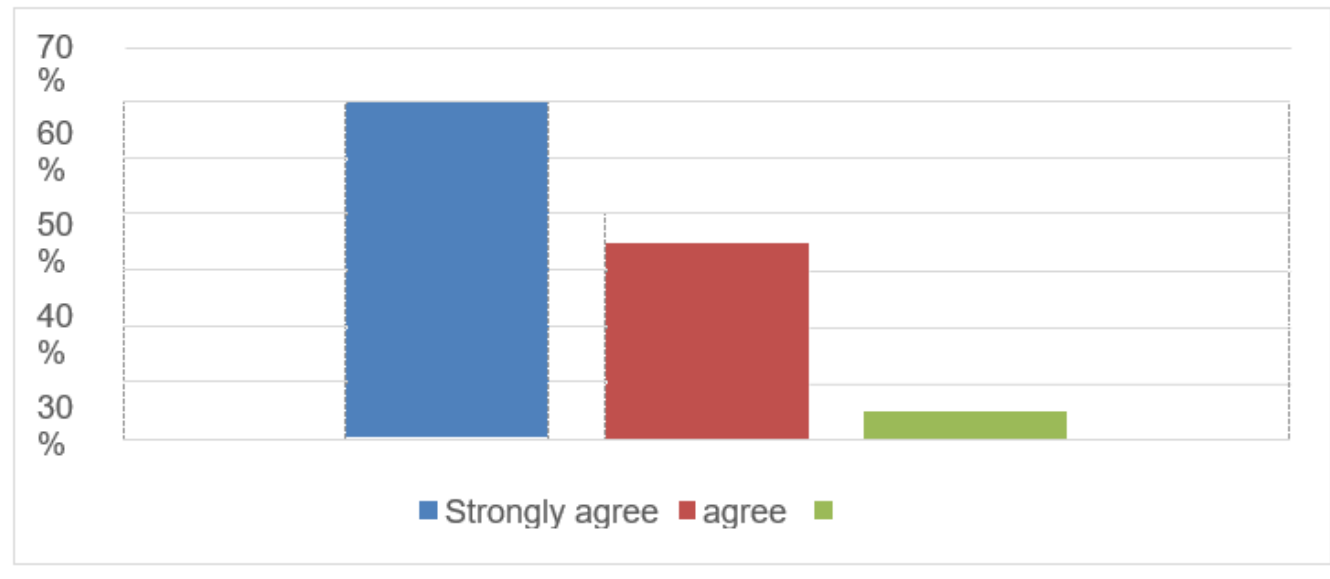




\section{Interpretation: -}

According to the above chart, about $60 \%$ of the employees strongly agree that the module has helped them to develop their own technical \& soft skills. $35 \%$ of the employees agree that the module has helped them to develop their own technical \& soft skills. Whereas $5 \%$ of the employees responded neutral.

\section{3) The module met with my expectations.}

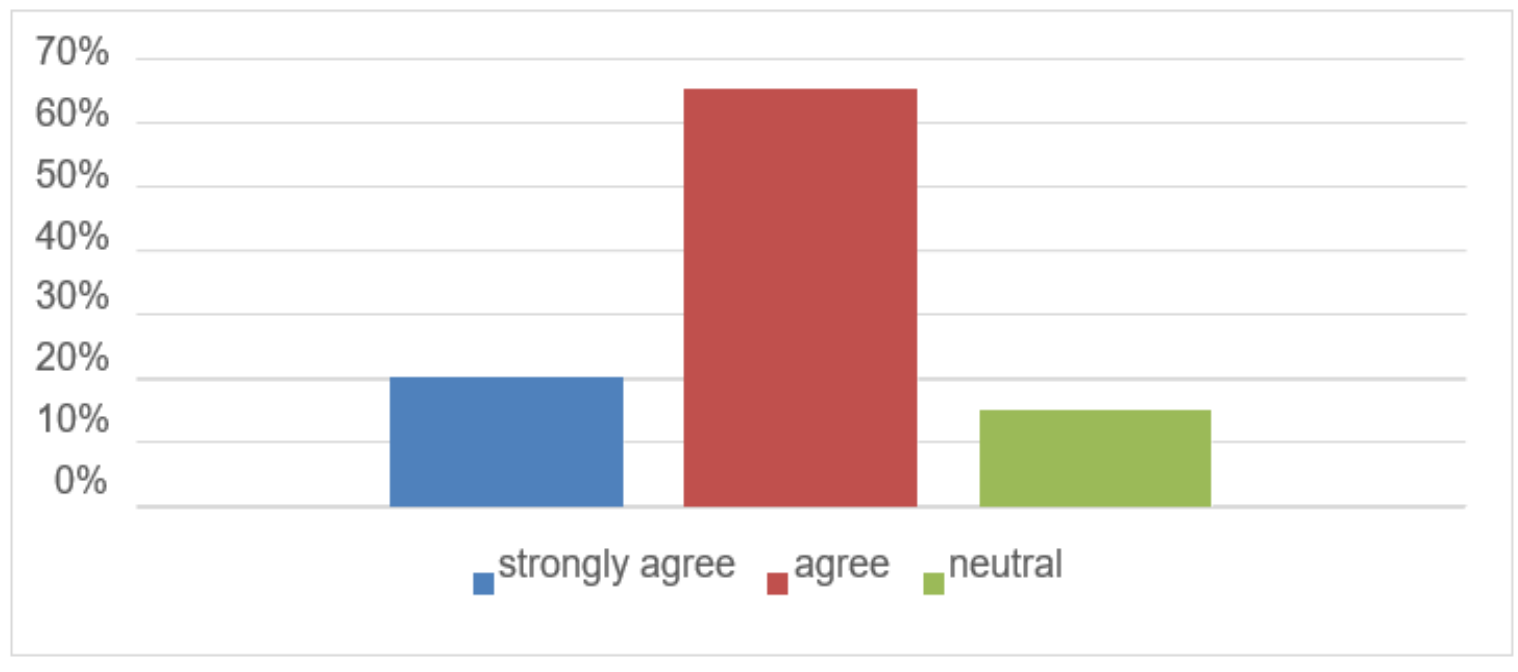

\section{Interpretation: -}

According to the above chart, about $20 \%$ of the employees strongly agree that the CSP Modules met with their expectations. $65 \%$ of the employees agree that the CSP modules met with their expectations. Whereas $15 \%$ of the employee's response was neutral.

14) Is certificate for completion of course in Custom Skill Program is satisfactory.

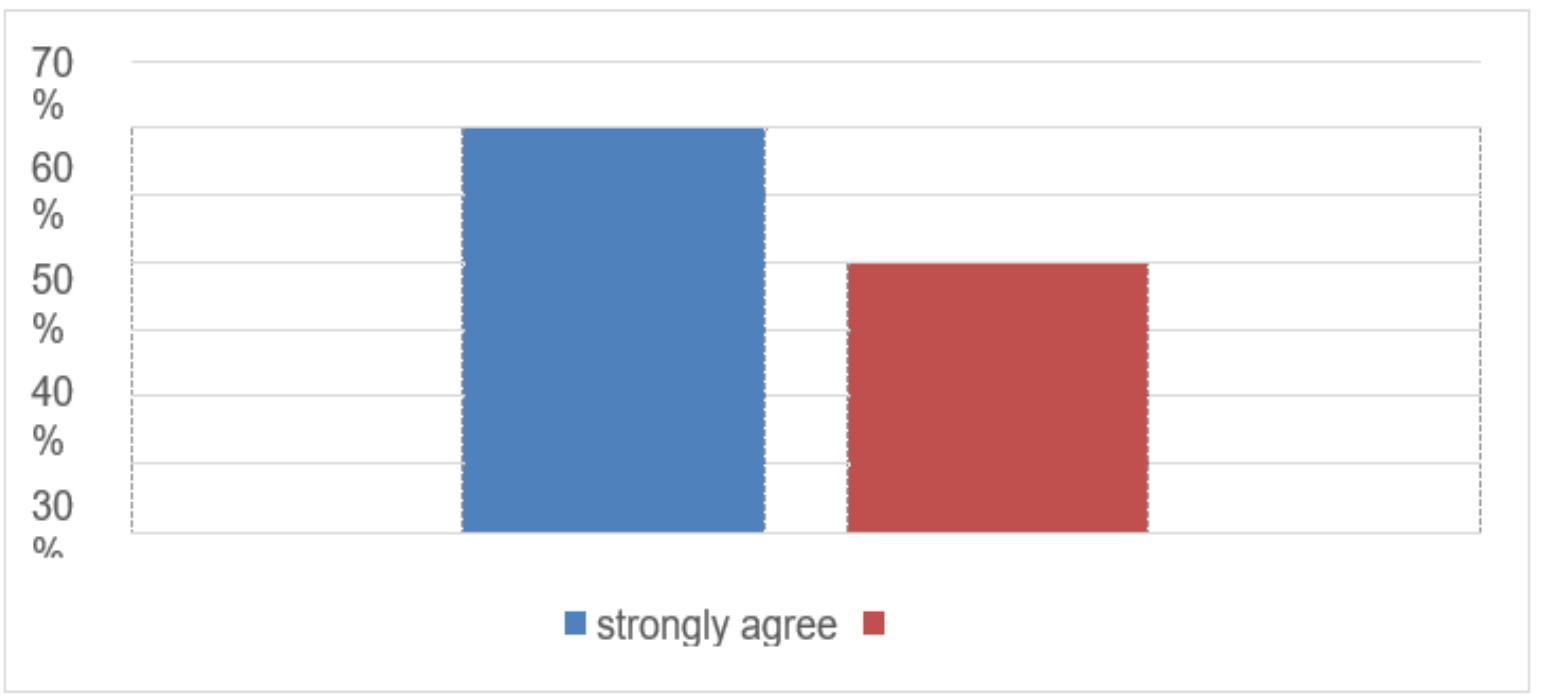

\section{Interpretation: -}

According to the above chart, about $60 \%$ of the employees strongly agree that the certificate for completion of course in CSP is satisfactory. $40 \%$ of the employees agree that the certificate for completion of course in CSP is satisfactory.

15) Satisfied with the overall quality of Custom Skill Program. 


\section{Available at: $\underline{w w w . i m p e r i a l p u b l i c a t i o n s . c o m}$}

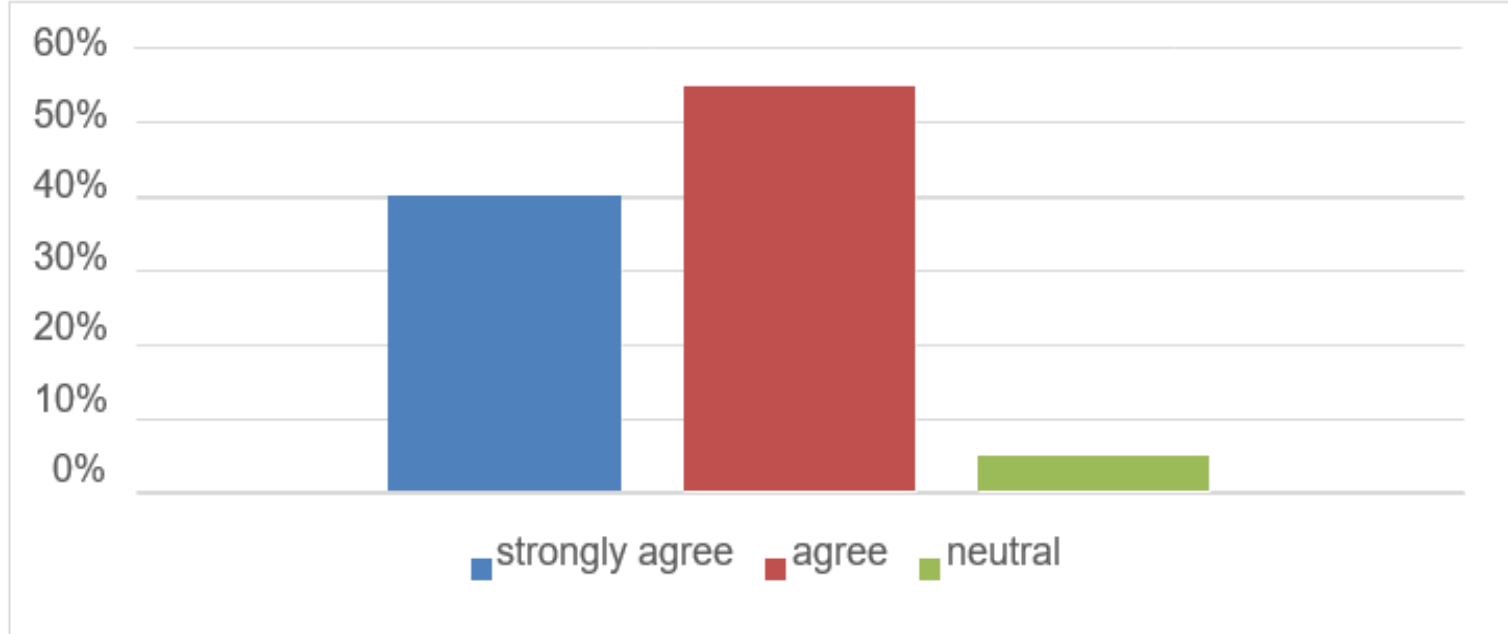

\section{Interpretation: -}

According to the above chart, about $40 \%$ of employees strongly agree that they are satisfied with the overall quality of CSP. $55 \%$ of employees agree that they are satisfied with the overall quality of CSP. 5\% of the employees responded neutral.

\section{FINDINGS}

From the above study, it is found out that floor sessions for awareness of CSP are useful for the employees. It has also found out that only 50 percent of the employees are satisfied with the program as they think course description and time in not sufficient. Many of the employees feels that the program is helping them in their job and they are learning a lot as, the course material is useful and it is helping in better understanding of the respective subjects and enhancing their skills. Thus, it is found from the study that CSP is considered to be effective in the organization. But, the employees expect more from the course as the courses are having too much pictures/flash data/exposed material and its more descriptive. Since, the program can help employees in making them more knowledgeable and efficient. With advancement of technology, it is necessary to make the more technically profound and enhance the skills. CSP is gaining importance day by day.

\section{LIMITATIONS}

- Certain policies and procedures restricted the employees/respondents to answer.

- The perception bias or attitude of the respondents also acted as a hurdle to the study.

\section{CONCLUSION}

The Custom Skill Program (CSP) in D's Entertainment Pvt. Ltd effectively helps in development of the employee's capability \& interpersonal skills which is directly related to organization's growth, productivity, evolution, and turnover. However, after the detailed study and analysis of the Custom Skill Program, it can be concluded that a few minor adjustments and additional features can be added to make the Custom Skill Program even more efficient.

\section{BIBLIOGRAPHY}

1. Alaina Kanfer, 2000-E-learning-A Review.

B. A. Buhari,

2. 2017-An Improved E-Learning System.

Hisyamuddin Hashim, Zaidatun Tasir,

3. 2014.E-Learning Readiness.

4. Jiang, M., Parent, S. and Eastmond, D. (2006) 'Effectiveness of web-based learning opportunities in a competency-based program', International Journal on E-Learning, vol. 5, no. 3, pp. 353-360.

5. Lobato, J. (2006) 'Alternative perspectives on the transfer oflearning: History, issues, and 
challenges for future research', Journal of the Learning Sciences, vol. 15(4), 431-449.

6. M. Changizi, 2010-Introduction to E-learning.

7. Mousazadeh Somayeh, Maryam Dehghani, Farzaneh Mozaffari, 2016-The effectiveness of Elearning in learning

8. Tagreed Kattoua, Prof. Musa Al-Lozi, 2016-A Review of Literature on E-Learning Systems.

9. Torbjörn Holmström Jenny Pitkänen, 2012- Elearning in higher education

10. Ur T.A. \&WeggenC.C. (2000)Teachers and Educational Quality: Monitoring Global Needs. Longitudinal Field Studies.' Management Science46, (2) 186-204.

11. Wentling T.L, Waight C, Gallagher J, La Fleur J, Wang C, Kanfer A. (2000). E-learning - a review of literature.Knowledge and Learning Systems Group NCSA9.1-73.

12. Yang, N. \&Arjomand, L. H. (1999).An Exploratory Investigation of Online Programs," Academy of EducationalLeadership Journal, 3 (2), 17-29. 